\title{
An Analytical Solution of Partially Penetrating Hydraulic Fractures in a Box-Shaped Reservoir
}

\author{
He Zhang, ${ }^{1,2}$ Xiaodong Wang, ${ }^{1,2}$ and Lei Wang ${ }^{1,2}$ \\ ${ }^{1}$ School of Energy Resources, China University of Geosciences, Beijing 100083, China \\ ${ }^{2}$ Beijing Key Laboratory of Unconventional Natural Gas Geology Evaluation and Development Engineering, Beijing 100083, China \\ Correspondence should be addressed to Lei Wang; wanglei1986sp@foxmail.com
}

Received 19 August 2014; Revised 8 December 2014; Accepted 8 December 2014

Academic Editor: Shaofan Li

Copyright (c) $2015 \mathrm{He}$ Zhang et al. This is an open access article distributed under the Creative Commons Attribution License, which permits unrestricted use, distribution, and reproduction in any medium, provided the original work is properly cited.

\begin{abstract}
This paper presents a new method to give an analytical solution in Laplace domain directly that is used to describe pressure transient behavior of partially penetrating hydraulic fractures in a box-shaped reservoir with closed boundaries. The basic building block of the method is to solve diffusivity equation with the integration of Dirac function over the distance that is presented for the first time. Different from the traditional method of using the source solution and Green's function presented by Gringarten and Ramey, this paper uses Laplace transform and Fourier transform to solve the diffusivity equation and the analytical solution obtained is accurate and simple. The effects of parameters including fracture height, fracture length, the position of the fracture, and reservoir width on the pressure and pressure derivative are fully investigated. The advantage of the analytical solution is easy to incorporate storage coefficient and skin factor. It can also reduce the amount of computation and compute efficiently and quickly.
\end{abstract}

\section{Introduction}

Hydraulic fracturing technology has been a common application in the oil and gas industry during the last two decades. More and more attentions were focused on the study of pressure transient behavior of hydraulically fractured wells. In most published literatures, hydraulic fractures were assumed to be fully penetrating the formation. Limited efforts have been made to investigate the effects of partially penetrating fracture height on the performance of wells. In practice, fully penetrating fractures may lead to an early or immediate water or gas breakthrough in a reservoir with bottom water or gas cap in contact, whereas partially penetrating fractures may be the only way to prevent the early breakthrough [1-3].

No matter the problem of wells with or without hydraulic fractures, most scholars considered the fully penetrating wells or fully penetrating hydraulic fractures. However the issue of partial penetration is always ignored. In the early time, some scholars presented some methods to study partially penetrating wells. Muskat, Nisle, Brons and Marting, and Papatzacos used the method of images [4], Streltsova-Adams [5] used Laplace and Hankel transformations, and Buhidma and Raghavan [6] used Green's function to solve the problem to partial penetration well in a reservoir. Later Yeh and Reynolds [7] used a numerical simulator to present some type curves for partial penetration, multilayered reservoirs with transient crossflow. In the late time, Ozkan and Raghavan [8] proposed a solution for a limited-entry slanted well in an infinite reservoir with closed top and bottom boundaries using the Laplace transformation and Bui et al. [9] used the double-porosity formulation of Warren and Root for naturally fractured reservoir. Fuentes-Cruz and CamachoVelazquez [10] obtained the pressure transient behavior for partially penetrating wells completed in naturally fracturedvuggy reservoir by combination of Laplace transformation and finite Fourier transformation.

To solve the unsteady-state flow problem of fractures in the reservoir, most solutions were presented based on the using of the source solution and Green's function provided by Gringarten and Ramey [11] which can be used in combination with Newman's product method to generate solutions for different reservoir flow problem. At first, the pressure behavior of the partially penetrating fractures was presented by Gringarten and Ramey Jr. [12] using Green's function. But 
the physical model only considered the closed upper and lower boundaries. Raghavan et al. [13] presented an analytical model that researched the effect of the vertical fracture height on the pressure transient behavior of a partially penetrated uniform-flux fractured well by evaluating the uniform-flux solution at a point in the fracture which was assumed to yield the infinite-conductivity solution. This model was an extension of the case of fully penetrating vertical fracture previously found by Gringarten et al. Rodriguez et al. $[14,15]$ presented semianalytical solution of the pressure transient behavior in a homogeneous and isotropic reservoir with a well intersected by a partially penetrating single vertical fracture of finite or infinite conductivity. However they did not investigate the effect of vertical fracture position on the wellbore pressure.

These previous solutions were quite significant to the later analysis of the pressure behavior of the partially penetrating fractures. Valkó and Amini [16] presented a method of distributed volume sources (DVS) to investigate a horizontal well with multiple transverse fractures in a box-shaped reservoir. The diffusivity equation considered a source term to calculate the pressure distribution and compute the production rate from a fracture. But it was only an approximate approach. Alpheus and Tiab [3] presented the analysis of the solution to the effect of partial penetration of an infinite conductivity hydraulic fracture on the pressure behavior of horizontal well extending in naturally fractured reservoirs. They founded that the duration of early linear flow regime is a function of the hydraulic fractures height. Although the mathematical model was obtained in Laplace domain with elliptical flow model, the method was complex and unclear because of the model that was obtained indirectly. Al Rbeawi and Tiab $[1,2]$ presented an analytical model in real time domain for the pressure behavior of a horizontal well with multiple vertical and inclined partially penetrating hydraulic fractures in an infinite homogenous reservoir to explain the pressure transient tests and forecast productivity of the well by using the instantaneous source function in three principal directions. Moreover, Lin and Zhu [17] developed a slab source method to evaluate performance of horizontal wells with or without fractures with consideration of the three-dimensional fracture geometry. However, the solution was also derived in real time domain, making it difficult to incorporate storage coefficient and skin factor that are usually obtained from the Laplace domain solution.

This study attempts to give some new insights in understanding the partially penetrating hydraulic fractures in a box-shaped reservoir. This paper presents an analytical solution that describes pressure transient behavior of partially penetrating fractures in a box-shaped reservoir and is successfully applied to examine effects of fracture half height, fracture half length, and reservoir width on performance of a fracture in a reservoir with closed boundaries based on pressure and pressure derivative concepts. Moreover the effect of the vertical position of the fracture on the pressure and pressure derivative is fully investigated. More specifically, the diffusivity equation is presented for the first time and the analytical solution of pressure transient behavior in Laplace domain is derived by using Laplace transform and Fourier

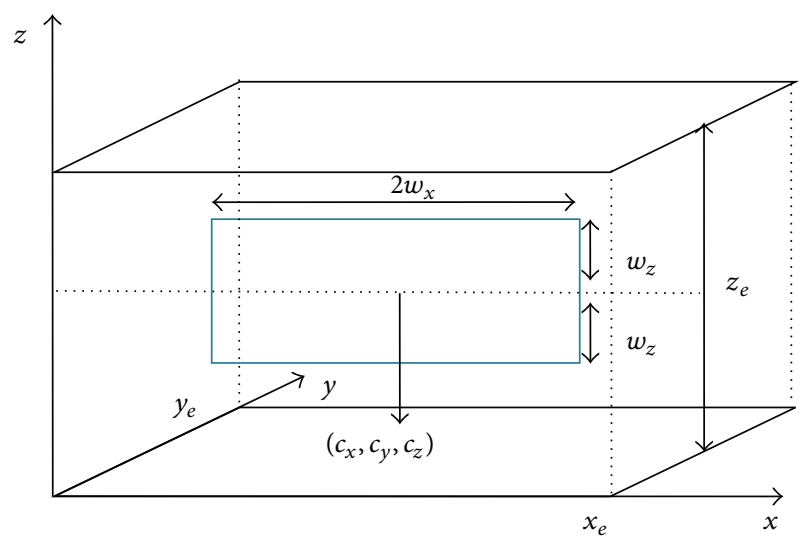

FIGURE 1: Schematic diagram of partially penetrating fracture.

transform. Then the bottomhole pressure in the real time domain can be obtained by using the inverse Laplace algorithm as proposed by Stehfest [18] subsequently. The result is validated accurately by comparing with previous results in the literature. The advantages of Laplace domain solution are that it can make it easy to incorporate storage coefficient and skin factor, can reduce the amount of computation, and improve the computational efficiently because it is unnecessary to scatter time.

\section{Mathematical Model}

Consider a partially penetrating hydraulic fracture in a closed homogenous box-shaped reservoir as shown in Figure 1. If we assume that all fluid withdrawal will be through the fracture, the fracture is partially penetrating the formation and the fracture can be simulated as plane source [2].

As shown in Figure 1, a partially penetrating fracture is placed in a reservoir with height $\left(z\right.$ direction) $z_{e}$, length ( $x$ direction) $x_{e}$, and width ( $y$ direction) $y_{e}$, having its dimension $2 w_{x}$ in $x$ direction and $2 w_{z}$ in $z$ direction. The formation has horizontal and vertical permeability $k_{h}$ and $k_{z}$, respectively. The fracture is assumed to be infinitely conductive and its position is $\left(c_{x}, c_{y}, c_{z}\right)$. The pressure is uniform initially throughout the reservoir and equal to $p_{i}$.

The analytical model for the pressure behavior of a fracture in a box-shaped reservoir can be derived based on the solution for the diffusivity equation in the porous media. The diffusivity equation that governs the flow is

$$
\eta_{h} \frac{\partial^{2} P}{\partial x^{2}}+\eta_{h} \frac{\partial^{2} P}{\partial y^{2}}+\eta_{z} \frac{\partial^{2} P}{\partial z^{2}}+\frac{Q B}{\phi c_{t}} H_{1} \times H_{2} \times H_{3}=\frac{\partial P}{\partial t},
$$

where $\phi$ is porosity, $c_{t}$ is total compressibility, $t$ is the time, $p$ is reservoir pressure, and $B$ is formation volume factor. The well produces slightly compressible fluid with constant viscosity $\mu$ at the total flow rate of $Q$, where

$$
\eta_{h}=\frac{k_{h}}{\phi \mu c_{t}} \quad \eta_{z}=\frac{k_{z}}{\phi \mu c_{t}} .
$$


We should notice that

$$
\mathrm{QB}=q 2 w_{x} 2 w_{z}
$$

where $q$ is the fluid withdraw per unit fracture surface area.

Reservoir pressure is initially constant

$$
p(x, y, z, 0)=p_{i} .
$$

The outer boundaries are assumed to be closed so that

$$
\left.\frac{\partial p}{\partial x}\right|_{x=0, x_{e}}=\left.0 \quad \frac{\partial p}{\partial y}\right|_{y=0, y_{e}}=\left.0 \quad \frac{\partial p}{\partial z}\right|_{z=0, z_{e}}=0
$$

$H_{1}, H_{2}$, and $H_{3}$ can be written, respectively, as

$$
\begin{aligned}
& H_{1}=\int_{c_{x}-w_{x}}^{c_{x}+w_{x}} \frac{1}{2 w_{x}} \delta\left(x-c_{x}\right) d c_{x} \\
& H_{2}=\delta\left(y-c_{y}\right) \\
& H_{3}=\int_{c_{z}-w_{z}}^{c_{z}+w_{z}} \frac{1}{2 w_{z}} \delta\left(z-c_{z}\right) d c_{z},
\end{aligned}
$$

where $\delta$ is Dirac function.

To simplify the problem we define dimensionless variables as the follows:

$$
\begin{gathered}
P_{D}=\frac{2 \pi k_{h} z_{e}\left(p_{i}-p\right)}{Q B \mu} \quad t_{D}=\frac{k_{h} t}{\phi \mu c_{t} L^{2}} \quad k_{h}=\sqrt{k_{x} k_{y}} \\
L_{D}=\frac{z_{e}}{L} \sqrt{\frac{k_{h}}{k_{z}}} \\
x_{D}=\frac{x}{L} \quad y_{D}=\frac{y}{L} \quad z_{D}=\frac{z}{z_{e}} \\
x_{e D}=\frac{x_{e}}{L} \quad y_{e D}=\frac{y_{e}}{L} \quad z_{e D}=\frac{z_{e}}{z_{e}}=1 \\
w_{x D}=\frac{w_{x}}{L} \quad w_{z D}=\frac{w_{z}}{z_{e}} \\
c_{x D}=\frac{c_{x}}{L} \quad c_{y D}=\frac{c_{y}}{L} \quad c_{z D}=\frac{c_{z}}{z_{e}},
\end{gathered}
$$

where $L$ is the reference length.

Using the dimensionless variables (1) can be written as

$$
\frac{\partial^{2} P_{D}}{\partial x_{D}^{2}}+\frac{\partial^{2} P_{D}}{\partial y_{D}^{2}}+\frac{\partial^{2} P_{D}}{L_{D}^{2} \partial z_{D}^{2}}+2 \pi H_{1 D} \times H_{2 D} \times H_{3 D}=\frac{\partial P_{D}}{\partial t_{D}},
$$

where $H_{1}, H_{2}$, and $H_{3}$ can be written as

$$
\begin{aligned}
& H_{1 D}=\int_{c_{x D}-w_{x D}}^{c_{x D}+w_{x D}} \frac{1}{2 w_{x D}} \delta\left(x_{D}-c_{x D}\right) d c_{x D} \\
& H_{2 D}=\delta\left(y_{D}-c_{y D}\right) \\
& H_{3 D}=\int_{c_{z D}-w_{z D}}^{c_{z D}+w_{z D}} \frac{1}{2 w_{z D}} \delta\left(z_{D}-c_{z D}\right) d c_{z D}
\end{aligned}
$$

with

$$
\text { I.C.: } p_{D}\left(x_{D}, y_{D}, z_{D}, 0\right)=0
$$

$$
\begin{array}{ll}
\text { B.C.s: }\left.\frac{\partial p_{D}}{\partial x_{D}}\right|_{x_{D}=0, x_{e D}}=\left.0 \quad \frac{\partial p_{D}}{\partial y_{D}}\right|_{y_{D}=0, y_{e D}}=0 \\
\left.\frac{\partial p_{D}}{\partial z_{D}}\right|_{z_{D}=0, z_{e D}}=0 .
\end{array}
$$

The Laplace transform with respect to time is defined as

$$
\tilde{p}_{D}\left(r_{D}, s\right)=\int_{0}^{\infty} p_{D}\left(r_{D}, s\right) e^{-s t_{D}} d t_{D}
$$

By applying Laplace transform to (8), we obtain

$$
\frac{\partial^{2} \tilde{p}_{D}}{\partial x_{D}^{2}}+\frac{\partial^{2} \tilde{p}_{D}}{\partial y_{D}^{2}}+\frac{\partial^{2} \tilde{p}_{D}}{L_{D}^{2} \partial z_{D}^{2}}+2 \pi \frac{H_{1 D} \times H_{2 D} \times H_{3 D}}{s}=s \widetilde{p}_{D} .
$$

Outer boundary conditions in Laplace space are

$$
\begin{gathered}
\left.\frac{\partial \widetilde{p}_{D}}{\partial x_{D}}\right|_{x_{D}=0, x_{e D}}=\left.0 \quad \frac{\partial \widetilde{p}_{D}}{\partial y_{D}}\right|_{y_{D}=0, y_{e D}}=0 \\
\left.\frac{\partial \widetilde{p}_{D}}{\partial z_{D}}\right|_{z_{D}=0, z_{e D}}=0 .
\end{gathered}
$$

Fourier cosine transform with respect to $x_{D}$ can be defined as

$$
\bar{p}_{D}\left(u_{n}\right)=\int_{0}^{x_{e D}} p_{D} \cos \left(u_{n} x_{D}\right) d x_{D}
$$

The characteristic equation is defined as

$$
\sin \left(u_{m} x_{e D}\right)=0
$$

By solving (15), the characteristic number is obtained as follows:

$$
u_{m}=\frac{m \pi}{x_{e D}}
$$


Based on the concept of Fourier cosine transform, the Fourier transform of the $H_{1 D}, H_{2 D}$, and $H_{3 D}$ function, respectively, is

$$
\begin{aligned}
\bar{H}_{1 D}= & \int_{0}^{x_{e D}} \int_{c_{x D}-w_{x D}}^{c_{x D}+w_{x D}} \frac{1}{2 w_{x D}} \delta\left(x_{D}-c_{x D}\right) d c_{x D} \\
& \cdot \cos \left(u_{m} x_{D}\right) d x_{D} \\
= & \frac{\left\{\sin \left[u_{m}\left(c_{x D}+w_{x D}\right)\right]-\sin \left[u_{m}\left(c_{x D}-w_{x D}\right)\right]\right\}}{2 u_{m} w_{x D}}
\end{aligned}
$$

$$
\bar{H}_{2 D}=\int_{0}^{y_{e D}} \delta\left(y_{D}-c_{y D}\right) \cos \left(v_{n} y_{D}\right) d y_{D}=\cos \left(v_{n} c_{y D}\right)
$$

$$
\begin{aligned}
& \bar{H}_{3 D}= \int_{0}^{z_{e D}} \int_{c_{z D}-w_{z D}}^{c_{z D}+w_{z D}} \frac{1}{2 w_{z D}} \delta\left(z_{D}-c_{z D}\right) d c_{z D} \\
& \cdot \cos \left(w_{p} z_{D}\right) d z_{D} \\
&=\frac{\left\{\sin \left[w_{p}\left(c_{z D}+w_{z D}\right)\right]-\sin \left[w_{p}\left(c_{z D}-w_{z D}\right)\right]\right\}}{2 w_{p} w_{z D}} .
\end{aligned}
$$

The first Fourier cosine transform of (12) on the variable $x_{D}$ is

$$
-u_{m}^{2} \overline{\widetilde{p}}_{D}+\frac{\partial^{2} \widetilde{p}_{D}}{\partial y_{D}^{2}}+\frac{\partial^{2} \widetilde{p}_{D}}{L_{D}^{2} \partial z_{D}^{2}}+2 \pi \frac{\bar{H}_{1 D} \times H_{2 D} \times H_{3 D}}{s}=s \overline{\widetilde{p}}_{D}
$$

The second Fourier cosine transform of (18) on the variable $y_{D}$ is

$$
-u_{m}^{2} \overline{\overline{\widetilde{p}}}_{D}-v_{n}^{2} \overline{\overline{\widetilde{p}}}_{D}+\frac{\partial^{2} \overline{\overline{\vec{p}}}_{D}}{L_{D}^{2} \partial z_{D}^{2}}+2 \pi \frac{\bar{H}_{1 D} \times \bar{H}_{2 D} \times H_{3 D}}{s}=s \overline{\overline{\widetilde{p}}}_{D}
$$

For the third Fourier cosine transform of (19) on the variable $z_{D}$, we obtain

$$
-u_{m}^{2} \overline{\overline{\widetilde{p}}}_{D}-v_{n}^{2} \overline{\overline{\widetilde{p}}}_{D}-\frac{w_{p}^{2}}{L_{D}^{2}} \overline{\bar{p}}_{D}+2 \pi \frac{\bar{H}_{1 D} \times \bar{H}_{2 D} \times \bar{H}_{3 D}}{s}=s \overline{\overline{\widetilde{p}}}_{D}
$$

where

$$
u_{m}=\frac{m \pi}{x_{e D}} \quad v_{n}=\frac{n \pi}{y_{e D}} \quad w_{p}=\frac{p \pi}{z_{e D}} .
$$

According to the following equation

$$
P_{D}\left(x_{D}\right)=\sum_{m=1}^{\infty} \frac{\cos \left(u_{m} x_{D}\right)}{N(n)} \bar{P}_{D}\left(u_{m}\right)
$$

taking the first Fourier inverse transform of (20) on the variable $z_{D}$, the solution can be expressed as follows:

$$
\begin{aligned}
s \overline{\overline{\vec{p}}}_{D}= & 2 \pi \frac{1}{z_{e D}} \bar{H}_{1 D} \times \bar{H}_{2 D} \times \frac{1}{\left(s+u_{m}^{2}+v_{n}^{2}\right)} \\
& +2 \pi \bar{H}_{1 D} \times \bar{H}_{2 D} \\
& \times \frac{2}{z_{e D}} \sum_{p=1}^{\infty} \cos \left(w_{p} z_{D}\right) \bar{H}_{3 D} \frac{1}{\left(s+u_{m}^{2}+v_{n}^{2}+w_{p}^{2} / L_{D}^{2}\right)} .
\end{aligned}
$$

The second Fourier inverse transform of (19) on the variable $y_{D}$ is

$$
\begin{aligned}
s \overline{\widetilde{p}}_{D}= & 2 \pi \frac{1}{y_{e D}} \frac{1}{z_{e D}} \frac{\bar{H}_{1 D}}{\left(s+u_{m}^{2}\right)} \\
& +2 \pi \frac{2}{y_{e D}} \bar{H}_{1 D} \sum_{n=1}^{\infty} \frac{1}{z_{e D}} \cos \left(v_{n} y_{D}\right) \frac{\bar{H}_{2 D}}{\left(s+u_{m}^{2}+v_{n}^{2}\right)} \\
& +2 \pi \frac{1}{y_{e D}} \bar{H}_{1 D} \frac{2}{z_{e D}} \sum_{p=1}^{\infty} \cos \left(w_{p} z_{D}\right) \frac{\bar{H}_{3 D}}{\left(s+u_{m}^{2}+w_{p}^{2} / L_{D}^{2}\right)} \\
& +2 \pi \frac{2}{y_{e D}} \frac{2}{z_{e D}} \bar{H}_{1 D} \\
& \times \sum_{n=1}^{\infty} \sum_{p=1}^{\infty} \cos \left(v_{n} y_{D}\right) \cos \left(w_{p} z_{D}\right) \\
& \cdot \frac{\bar{H}_{2 D} \bar{H}_{3 D}}{\left(s+u_{m}^{2}+v_{n}^{2}+w_{p}^{2} / L_{D}^{2}\right)} .
\end{aligned}
$$

The third Fourier inverse transform of (18) on the variable $x_{D}$ is

$$
\begin{aligned}
s \tilde{p}_{D}= & \frac{2 \pi}{x_{e D} y_{e D} z_{e D} s} \\
& +\frac{4 \pi}{x_{e D} y_{e D} z_{e D}} \sum_{m=1}^{\infty} \cos \left(u_{m} x_{D}\right) \frac{\bar{H}_{1 D}}{\left(s+u_{m}^{2}\right)} \\
& +\frac{4 \pi}{x_{e D} y_{e D} z_{e D}} \sum_{n=1}^{\infty} \cos \left(v_{n} y_{D}\right) \frac{\bar{H}_{2 D}}{\left(s+v_{n}^{2}\right)} \\
& +\frac{8 \pi}{x_{e D} y_{e D} z_{e D}} \\
& \cdot \sum_{n=1}^{\infty} \sum_{m=1}^{\infty} \cos \left(v_{n} y_{D}\right) \cos \left(u_{m} x_{D}\right) \frac{\bar{H}_{1 D} \bar{H}_{2 D}}{\left(s+u_{m}^{2}+v_{n}^{2}\right)} \\
& +\frac{4 \pi}{x_{e D} y_{e D} z_{e D}} \sum_{p=1}^{\infty} \cos \left(w_{p} z_{D}\right) \frac{\bar{H}_{3 D}}{\left(s+w_{p}^{2} / L_{D}^{2}\right)} \\
& +\frac{8 \pi}{x_{e D} y_{e D} z_{e D}}
\end{aligned}
$$




$$
\begin{aligned}
& \cdot \sum_{m=1}^{\infty} \sum_{p=1}^{\infty} \cos \left(w_{p} z_{D}\right) \cos \left(u_{m} x_{D}\right) \frac{\bar{H}_{1 D} \bar{H}_{3 D}}{\left(s+u_{m}^{2}+w_{p}^{2} / L_{D}^{2}\right)} \\
& +\frac{8 \pi}{x_{e D} y_{e D} z_{e D}} \\
& \cdot \sum_{n=1}^{\infty} \sum_{p=1}^{\infty} \cos \left(v_{n} y_{D}\right) \cos \left(w_{p} z_{D}\right) \frac{\bar{H}_{2 D} \bar{H}_{3 D}}{\left(s+v_{n}^{2}+w_{p}^{2} / L_{D}^{2}\right)} \\
& +\frac{16 \pi}{x_{e D} y_{e D} z_{e D}} \\
& \cdot \sum_{m=1}^{\infty} \sum_{n=1}^{\infty} \sum_{p=1}^{\infty} \cos \left(v_{n} y_{D}\right) \cos \left(w_{p} z_{D}\right) \cos \left(u_{m} x_{D}\right) \\
& \cdot \frac{\bar{H}_{1 D} \bar{H}_{2 D} \bar{H}_{3 D}}{\left(s+u_{m}^{2}+v_{n}^{2}+w_{p}^{2} / L_{D}^{2}\right)} .
\end{aligned}
$$

Applying (17b) and following equation

$$
\begin{aligned}
& 2 \cos \left(v_{n} c_{y D}\right) \cos \left(v_{n} w_{y D}\right) \\
&= \cos \left(v_{n}\left(c_{y D}-w_{y D}\right)\right)+\cos \left(v_{n}\left(c_{y D}+w_{y D}\right)\right) \\
&= \cos \left(\frac{n \pi}{y_{e D}}\left(c_{y D}-w_{y D}\right)\right)+\cos \left(\frac{n \pi}{y_{e D}}\left(c_{y D}+w_{y D}\right)\right) \\
& \sum_{k=1}^{\infty} \frac{\cos k x}{k^{2}+\alpha^{2}}=\frac{\pi}{2 \alpha} \frac{\cosh \alpha(\pi-x)}{\sinh \alpha \pi}-\frac{1}{2 \alpha^{2}}
\end{aligned}
$$

we can obtain

$$
\begin{gathered}
\sum_{n=1}^{\infty} \frac{2 \cos \left(v_{n} y_{D}\right) \cos \left(v_{n} c_{y D}\right)}{s+v_{n}^{2}} \\
=\frac{y_{e D}}{2 \sqrt{s}}\left(\cosh \sqrt{s}\left(y_{e D}-\left(y_{D}-c_{y D}\right)\right)\right. \\
\left.+\cosh \sqrt{s}\left(y_{e D}-\left(y_{D}+c_{y D}\right)\right)\right) \\
\cdot\left(\sinh \left(\sqrt{s} y_{e D}\right)\right)^{-1}-\frac{1}{s} .
\end{gathered}
$$

Using the same method, the following formulas can be written as

$$
\begin{gathered}
\sum_{n=1}^{\infty} \frac{2 \cos \left(v_{n} y_{D}\right) \cos \left(v_{n} c_{y D}\right)}{s+u_{m}^{2}+v_{n}^{2}} \\
=\frac{y_{e D}}{2 \varepsilon_{m}}\left(\cosh \varepsilon_{m}\left(y_{e D}-\left(y_{D}-c_{y D}\right)\right)\right. \\
\left.+\cosh \varepsilon_{m}\left(y_{e D}-\left(y_{D}+c_{y D}\right)\right)\right) \\
\cdot\left(\sinh \left(\varepsilon_{m} y_{e D}\right)\right)^{-1}-\frac{1}{\varepsilon_{m}^{2}}
\end{gathered}
$$

$$
\begin{gathered}
\sum_{p=1}^{\infty} \frac{2 \cos \left(v_{n} y_{D}\right) \cos \left(v_{n} c_{y D}\right)}{s+v_{n}^{2}+w_{p}^{2} / L_{D}^{2}} \\
=\frac{y_{e D}}{2 \varepsilon_{p}}\left(\cosh \varepsilon_{p}\left(y_{e D}-\left(y_{D}-c_{y D}\right)\right)\right. \\
\left.+\cosh \varepsilon_{p}\left(y_{e D}-\left(y_{D}+c_{y D}\right)\right)\right) \\
\cdot\left(\sinh \left(\varepsilon_{p} y_{e D}\right)\right)^{-1}-\frac{1}{\varepsilon_{p}^{2}} \\
\sum_{p=1}^{\infty} \frac{2 \cos \left(v_{n} y_{D}\right) \cos \left(v_{n} c_{y D}\right)}{s+u_{m}^{2}+v_{n}^{2}+w_{p}^{2} / L_{D}^{2}} \\
\left.=\frac{y_{e D}\left(\cosh \varepsilon_{m p}\left(y_{e D}-\left(y_{D}-c_{y D}\right)\right)\right.}{2 \varepsilon_{m p}}+\cosh \varepsilon_{m p}\left(y_{e D}-\left(y_{D}+c_{y D}\right)\right)\right)
\end{gathered}
$$$$
\cdot\left(\sinh \left(\varepsilon_{m p} y_{e D}\right)\right)^{-1}-\frac{1}{\varepsilon_{m p}^{2}},
$$

where

$$
\begin{gathered}
\varepsilon_{m}^{2}=s+u_{m}^{2}=s+\frac{m^{2} \pi^{2}}{x_{e D}^{2}} \\
\varepsilon_{p}^{2}=s+w_{p}^{2}=s+\frac{p^{2} \pi^{2}}{L_{D}^{2}} \\
\varepsilon_{m p}^{2}=s+u_{m}^{2}+w_{p}^{2}=s+\frac{m^{2} \pi^{2}}{x_{e D}^{2}}+\frac{p^{2} \pi^{2}}{L_{D}^{2}} .
\end{gathered}
$$

Substitute (27)-(29) in (25) and simplify the equation is calculated as

$$
\begin{aligned}
s \tilde{p}_{D}= & \frac{\pi}{x_{e D} z_{e D}} \\
& \cdot\left(\left[\cosh \sqrt{s}\left(y_{e D}-y_{D}+c_{y D}\right)\right.\right. \\
& \left.\left.\quad+\cosh \sqrt{s}\left(y_{e D}-y_{D}-c_{y D}\right)\right]\right) \\
& \cdot\left(\sqrt{s} \sinh \sqrt{s} y_{e D}\right)^{-1} \\
+ & \frac{2 \pi}{x_{e D} z_{e D}} \sum_{m=1}^{\infty} \cos \left(u_{m} x_{D}\right) \frac{\cos \left(u_{m} c_{x D}\right) \sin \left(u_{m} w_{x D}\right)}{u_{m} w_{x D}} \\
& \times\left[\left(\cosh \varepsilon_{m}\left(y_{e D}-\left(y_{D}-y_{w D}\right)\right)\right.\right. \\
& \left.\quad+\cosh \varepsilon_{m}\left(y_{e D}-\left(y_{D}+y_{w D}\right)\right)\right) \\
& \left.+\left(\varepsilon_{m} \sinh \varepsilon_{m} y_{e D}\right)^{-1}\right] \\
& \frac{2 \pi}{x_{e D} z_{e D}} \sum_{p=1}^{\infty} \cos \left(w_{p} z_{D}\right) \frac{\cos \left(w_{p} c_{z D}\right) \sin \left(w_{p} w_{z D}\right)}{w_{p} w_{z D}}
\end{aligned}
$$




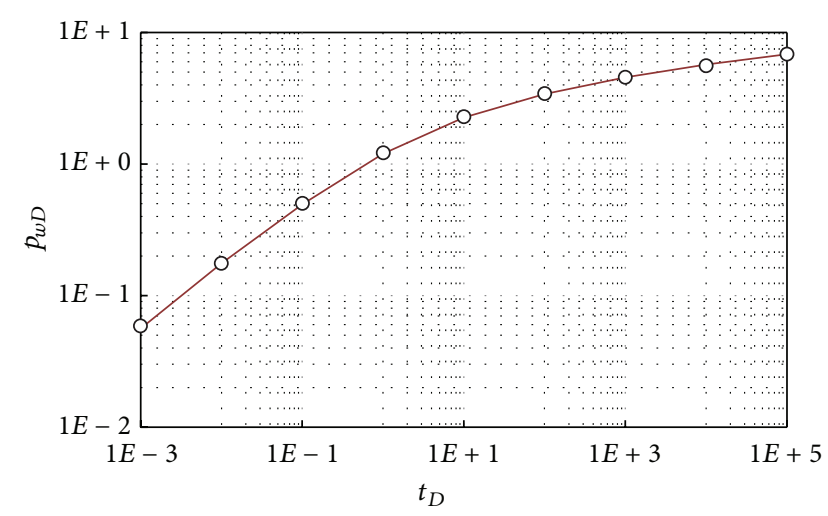

○ Kuchuk and Brighan

— This work

FIGURE 2: Model validation between this study and literature results.

$$
\begin{aligned}
& \times\left[\left(\cosh \varepsilon_{p}\left(y_{e D}-\left(y_{D}-y_{w D}\right)\right)\right.\right. \\
& \left.+\cosh \varepsilon_{p}\left(y_{e D}-\left(y_{D}+y_{w D}\right)\right)\right) \\
& \left.\cdot\left(\varepsilon_{p} \sinh \varepsilon_{p} y_{e D}\right)^{-1}\right] \\
& +\frac{4 \pi}{x_{e D} z_{e D}} \sum_{m=1}^{\infty} \sum_{p=1}^{\infty} \cos \left(w_{p} z_{D}\right) \cos \left(u_{m} x_{D}\right) \\
& \cdot \frac{\cos \left(u_{m} c_{x D}\right) \sin \left(u_{m} w_{x D}\right)}{u_{m} w_{x D}} \frac{\cos \left(w_{p} c_{z D}\right) \sin \left(w_{p} w_{z D}\right)}{w_{p} w_{z D}} \\
& \times\left[\frac { y _ { e D } } { 2 } \left(\cosh \varepsilon_{m p}\left(y_{e D}-\left(y_{D}-y_{w D}\right)\right)\right.\right. \\
& \left.\quad+\cosh \varepsilon_{m p}\left(y_{e D}-\left(y_{D}+y_{w D}\right)\right)\right) \\
& \left.\quad \cdot\left(\varepsilon_{m p} \sinh \varepsilon_{m p} y_{e D}\right)^{-1}\right] .
\end{aligned}
$$

Equation (30) is the mathematical model for pressure response of a partially penetrating hydraulic fracture in Laplace domain in dimensionless form. The solution in the real time domain can be obtained by using the inverse Laplace algorithm as proposed by Stehfest [18].

\section{Validation of the Method}

Kuchuk and Brighan [19] presented analytical solutions that are applicable to infinite-conductivity vertically fractured wells, elliptically shaped reservoirs, and anisotropic reservoirs producing at a constant rate or pressure. In order to validate the solution, we considered a special case that the fracture is full penetration; that is, $w_{z D}=0.5$. We obtained some data from the literature presented by Kuchuk and Brighan. Figure 2 shows a comparison between the results from Kuchuk and Brighan and this work for the fully penetrating infinite-conductivity isotropic case. We can see a very
TABLE 1: Basic data of the system.

\begin{tabular}{lc}
\hline Dimensionless parameter & Value \\
\hline Reservoir length $x_{e D}$ & 4000 \\
Reservoir width $y_{e D}$ & 4000 \\
Reservoir height $z_{e D}$ & 1 \\
Half fracture length $w_{x D}$ & 1 \\
Half fracture height $w_{z D}$ & 0.5 \\
Variable $L_{D}$ & 1 \\
Fracture position $c_{x D}, c_{y D}, c_{z D}$ & $(2000,2000,0.5)$ \\
\hline
\end{tabular}

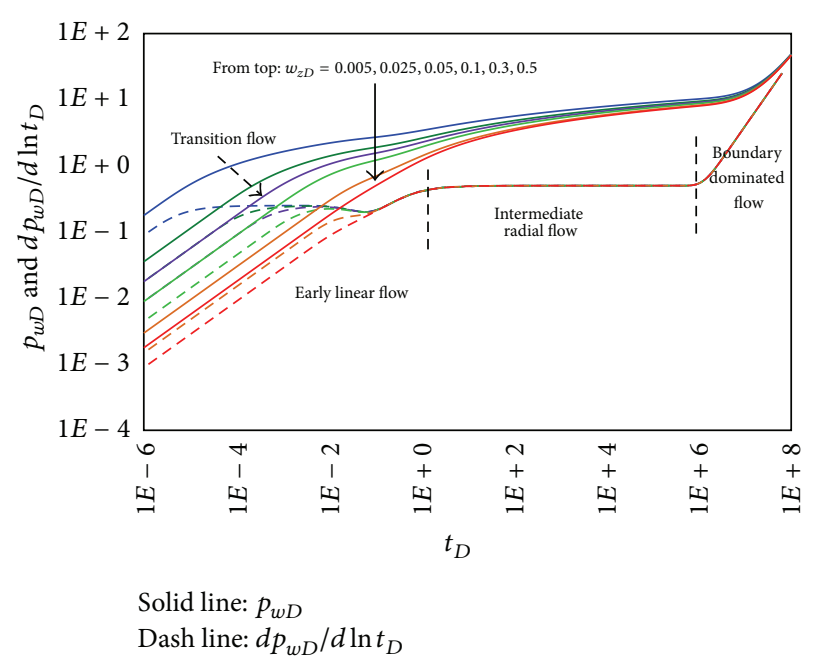

FIGURE 3: The effect of fracture height for fracture in the center.

good agreement between the solution in this paper and the literature, showing that the method in this study produces reliable transient pressure.

\section{Sensitivity Analysis}

Based on the analytical solution for a partially penetrating fracture in a box-shaped reservoir presented in the previous part, a sensitivity study for the parameters affecting the pressure and pressure derivative in the model is carried out. The intention of this study is to show the effect of each of these parameters on the dynamic behavior of a partially penetrating fracture in a box-shaped reservoir. We evaluate the pressure transient solution by varying the values of four parameters including the fracture half height, the fracture half length, the fracture position, and the reservoir width. As shown on the plots, the pressure and pressure derivative have different shapes for each combination of fracture height, fracture length, fracture position, and reservoir width. Dimensionless basic parameters used for simulating pressure transient response are presented in Table 1.

4.1. The Effect of Fracture Half Height and Off Center Fracture. Figure 3 depicts pressure and pressure derivative curves versus time for $w_{z D}=0.005,0.025,0.05,0.1,0.3,0.5$ with a fracture in the center of the reservoir, respectively (see 

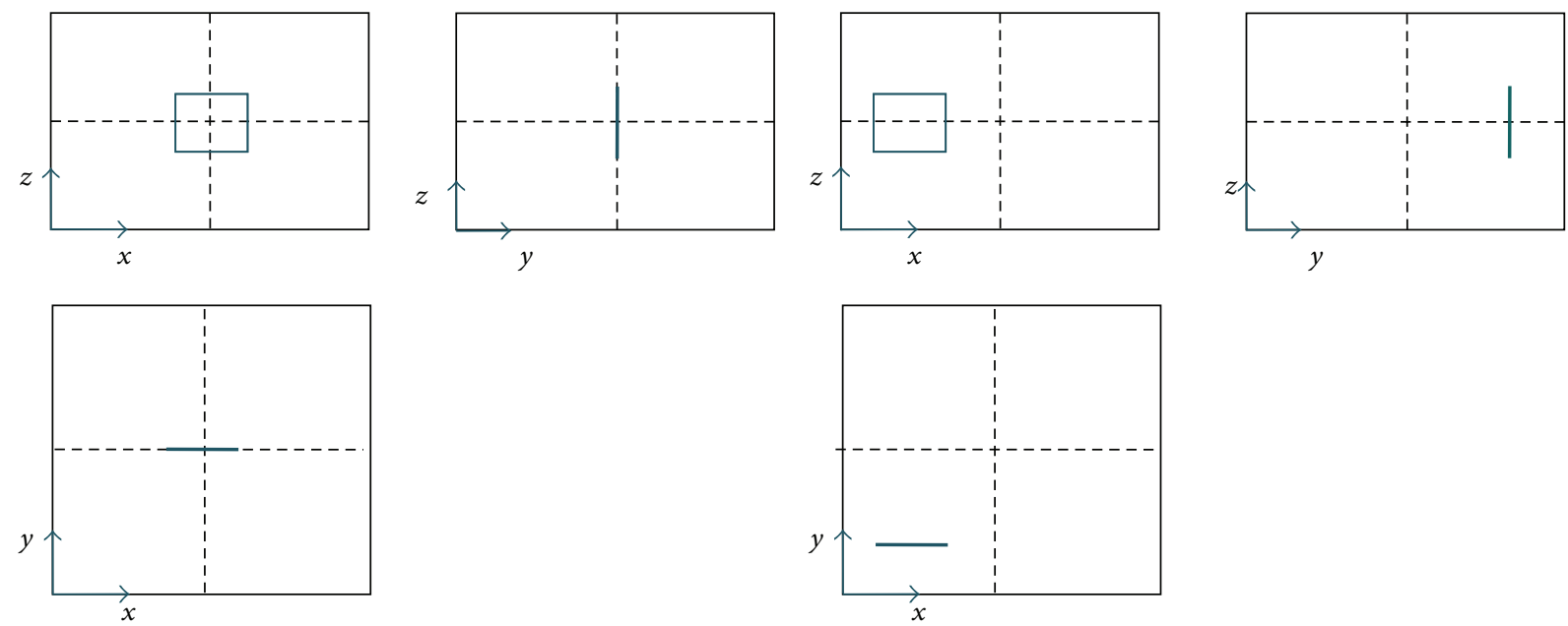

(a)

(b)

FIGURE 4: Schematic diagram of partially penetrating fracture.

Figure 4(a)). Other parameters are not changed in Table 1. Obviously, the pressure drop becomes larger as the fracture half height is decreased, which means that small fracture height will cause big pressure drop mainly in the early time period. The pressure drop for different $w_{z D}$ tends to be consistent as time goes on. As shown in the pressure derivative curves, the fracture height mainly influences the early linear flow and transition flow and has no effect on the intermediate radial flow and boundary dominated flow. The fluids which take place in the direction of the upper and lower boundaries towards the fracture because of the effect of the partially penetrating fracture could produce the transition flow. As shown in Figure 3, when the $w_{z D}=0.5$ (fully penetrating fracture), the transition flow cannot be seen from the pressure derivative curve. The end time of the early linear flow of the smaller $w_{z D}$ is shorter than that of larger $w_{z D}$. All pressure derivative curves for different $w_{z D}$ value are also parallel in early linear flow regime.

Figure 5 depicts pressure and pressure derivative curves versus time for $w_{z D}=0.005,0.025,0.05,0.1,0.3,0.5$ with a fracture in the off center of the reservoir, respectively (see Figure $4(\mathrm{~b}))$. The fracture is located at $(500,500,0.5)$ and other parameters are not changed as shown in Table 1. Comparing to the fracture in the center of the reservoir, the only difference is the number of the boundary dominated flows. The fluids flowing from the nearer boundaries and further boundaries towards the fracture cause first boundary dominated flow and second boundary dominated flow, respectively, because the distance of the off center fracture to each boundary ( $x$-direction boundary and $y$-direction boundary) is different at late time. According to the boundary dominated flow which occurs twice as seen from the pressure derivative curve we can judge the fracture is off the center.

\subsection{The Effect of Fracture Half Length and Off Center Fracture}

4.2.1. Small Half Penetration Ratio $\left(2 w_{z D}<0.5\right)$. Figure 6 shows the type curves for different value of fracture half

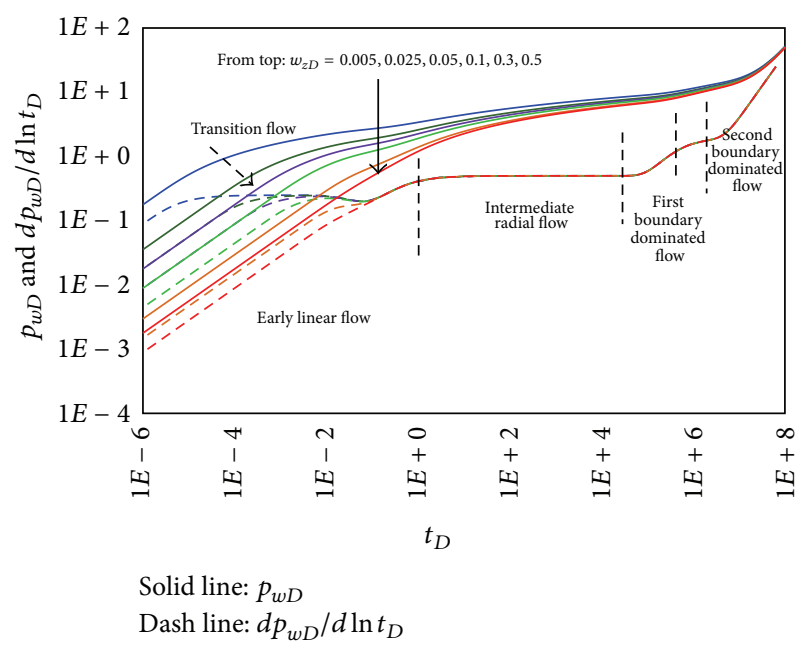

FIGURE 5: The effect of fracture height for fracture not in the center.

length $\left(w_{x D}=2,4,6,8\right.$, resp.). The fracture is in the center of the reservoir while remaining other parameters are unchanged as shown in Table 1. As expected, the smaller the fracture half length, the higher the dimensionless pressure drop, which implies that small fracture length will cause great pressure drop at the early time. As shown in the pressure derivative curves, the fracture length mainly influences the early linear flow and transition flow and has no effect on the radial flow and boundary dominated flow. Comparing with the type curves for a fully penetrating fracture, the pressure derivative of a partially penetrating fracture has higher values during early time period. Before the intermediate radial flow regime, the pressure derivative becomes larger when the fracture length $\left(w_{x D}\right)$ is decreased. For the same fracture height and reservoir thickness, the larger the dimensionless fracture half length $w_{x D}$ is, the longer it takes to reach radial flow regime in the reservoir. 


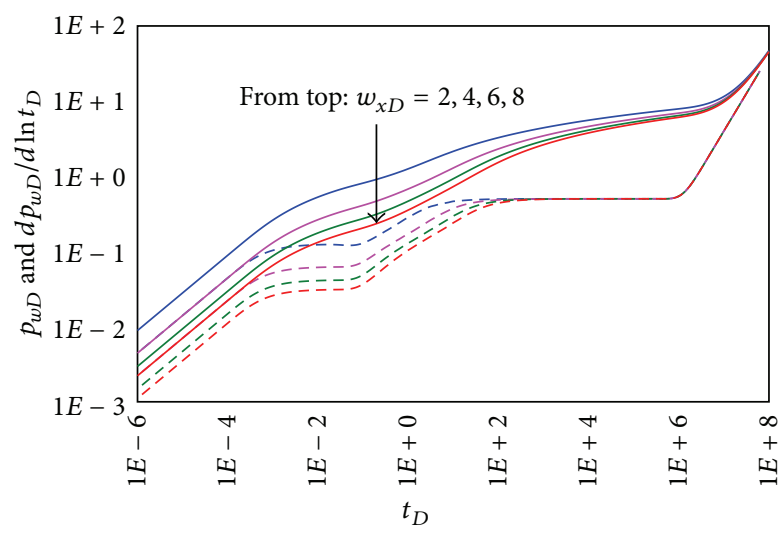

Solid line: $p_{w D}$

Dash line: $d p_{w D} / d \ln t_{D}$

FIGURE 6: The effect of fracture length at $w_{z D}=0.05$ for fracture in the center.

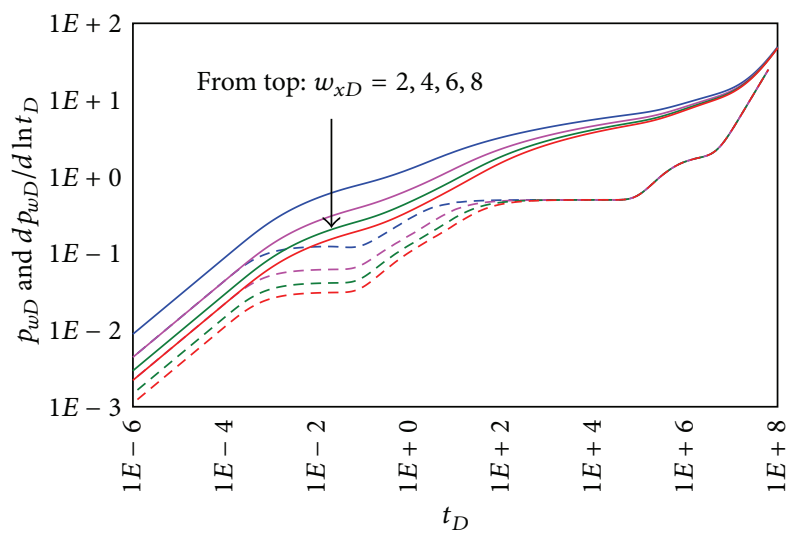

Solid line: $p_{w D}$

Dash line: $d p_{w D} / d \ln t_{D}$

FIGURE 7: The effect of fracture length at $w_{z D}=0.05$ for fracture not in the center.

Figure 7 depicts pressure and pressure derivative curves versus time for $w_{x D}=2,4,6,8$ with a fracture in the off center of the reservoir, respectively. The fracture is located at $(500,500,0.5)$ and other parameters are not changed as shown in Table 1. Comparing to Figure 6, the off center fracture mainly affects the boundary dominated flow. The boundary dominated flow regime appears twice followed by the intermediate radial flow.

4.2.2. Large Half Penetration Ratio $\left(2 w_{z D}>0.5\right)$. The effect of the fracture half length on pressure and pressure derivative when the fracture with large half penetration ratio is in the center of the reservoir is shown in Figure 8. Because of the large half penetration ratio, the pressure behavior in this case tends to be similar to the fully penetrating fractures $\left(w_{z D}=\right.$ 0.5 ) where other factors such as fracture dimension have the main influence. A slight transition regime appears at the initial production time followed by the early linear flow regime.

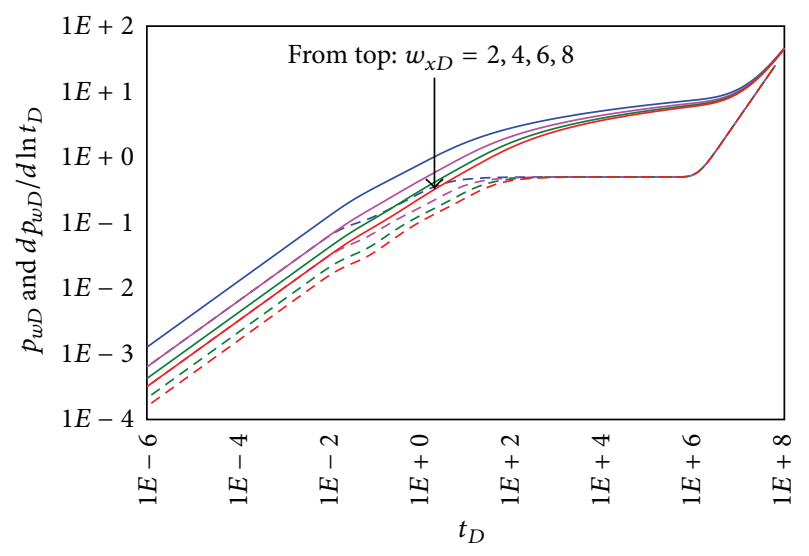

Solid line: $p_{w D}$

Dash line: $d p_{w D} / d \ln t_{D}$

FIGURE 8: The effect of fracture length at $w_{z D}=0.35$ for fracture in the center.

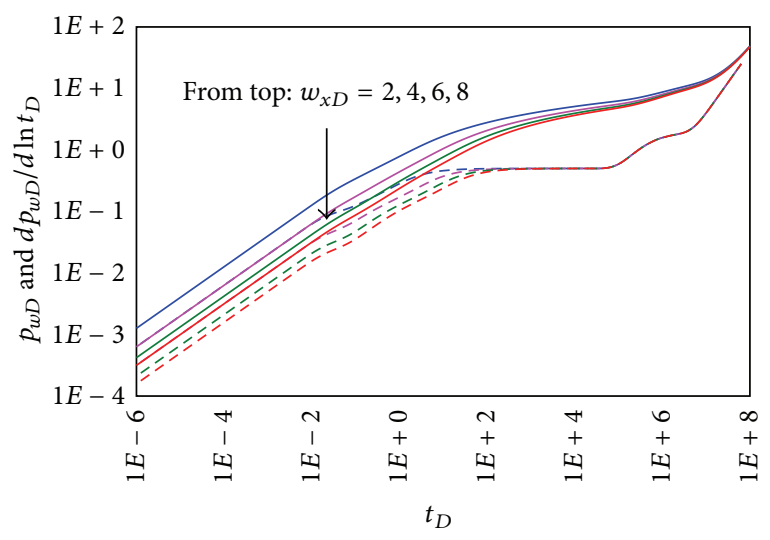

Solid line: $p_{w D}$

Dash line: $d p_{w D} / d \ln t_{D}$

FIGURE 9: The effect of fracture length at $w_{z D}=0.35$ for fracture not in the center.

Comparing with the type curves for a fully penetrating fracture, the pressure derivative of a partially penetrating fracture has higher values during early time period. The pressure drop is larger as the fracture length is decreased and the pressure derivative has the same rule before the radial flow regime.

Figure 9 depicts pressure and pressure derivative curves for $w_{x D}=2,4,6,8$ with a fracture in the off center of the reservoir, respectively. The position of the fracture is $\left(c_{x D}=500, c_{y D}=500, c_{z D}=0.5\right)$, and other parameters are not changed as shown in the Table 1 . We notice that the pressure and pressure derivative values for the case of partially penetrating fractures in the off center of the reservoir are very similar to that case of fully penetrating fractures. The only difference is that the boundary dominated flow regime appears twice. As such, the boundary dominated flow can be used to distinguish whether the fracture in the center of the reservoir. 


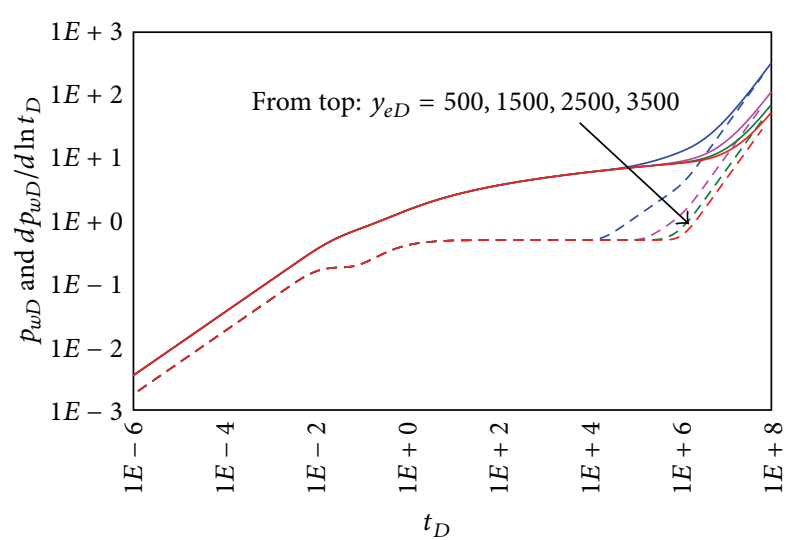

Solid line: $p_{w D}$

Dash line: $d p_{w D} / d \ln t_{D}$

Figure 10: The effect of reservoir width.

4.3. The Effect of the Reservoir Width. Figure 10 depicts pressure derivative curves versus time for $y_{e D}=500,1500$, 2500,3500 with a fracture in the center of the reservoir, respectively, while other parameters are not changed. Reservoir width mainly affects the boundary dominated flow regime. As seen in Figure 10, the starting time of the boundary dominated flow regime is affected by the dimensionless reservoir width. It is observed that the dimensionless pressure drop becomes larger as the dimensionless reservoir width is decreased, which means that a small reservoir will cause big pressure drop in the boundary dominated flow regime.

\section{Application of Type Curve Matching}

Type-curve matching is a quick method to estimate reservoir and fracture parameters. The following procedures illustrate how type curve matching is used to calculate reservoir and fracture characteristics such as permeability, fracture half length, and fracture half height.

Step 1. Plot pressure change $(\Delta p)$ and pressure derivative $(t \times$ $\left.\Delta p^{\prime}\right)$ values versus test time on a log-log graph.

Step 2. Obtain the best match of the data with one of the type curves.

Step 3. Read from an match point: $t_{M}, t_{D M}, \Delta p_{M}, p_{D M}, w_{z D}$, $w_{x D}, L_{D}$.

Step 4. Calculate $k_{h}$ :

$$
k_{h}=\frac{141 \cdot 2 Q B \mu p_{D}}{z_{e} \Delta p} .
$$

Step 5. Calculate $L$ :

$$
L=\sqrt{\frac{0.0002637 t_{M} k_{h}}{\phi \mu c_{t} t_{D M}}} .
$$

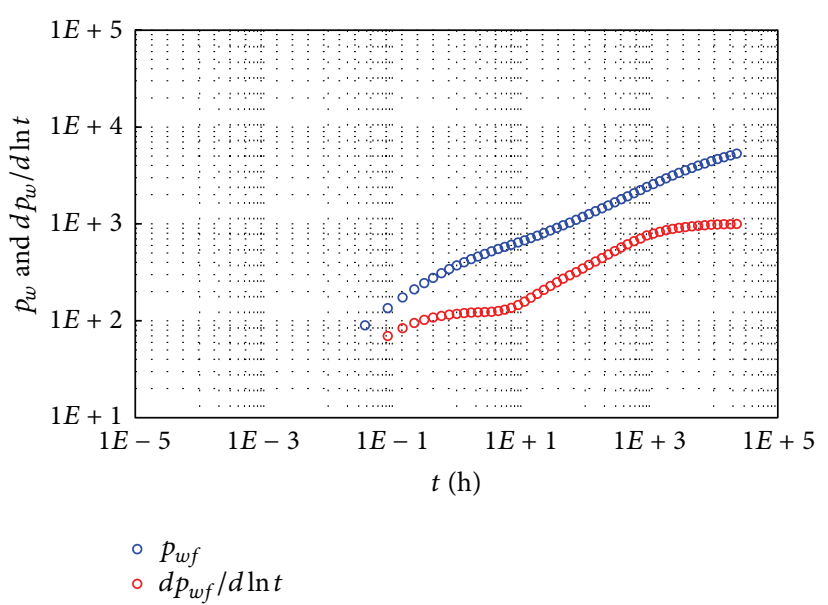

FIGURE 11: Pressure and pressure derivative plot for example.

Step 6. Calculate $k_{z}$ :

$$
k_{z}=\frac{k_{h}}{\left(L_{D} L / z_{e}\right)^{2}} .
$$

Step 7. Calculate the fracture half height:

$$
w_{z}=w_{z D} z_{e} .
$$

Step 8. Calculate the fracture half length:

$$
w_{x}=w_{x D} L .
$$

Example 1. Giving the reservoir and well data,

$$
\begin{gathered}
Q=500 \mathrm{STB} / \mathrm{D} \quad \phi=0.3 \quad \mu=4 \mathrm{cp} \\
B_{o}=1.4 \mathrm{bbl} / \mathrm{STB} \quad z_{e}=100 \mathrm{ft} \\
c_{t}=4 \times 10^{-6} \mathrm{psi}^{-1} \quad r_{w}=0.25 \mathrm{ft} \\
p_{i}=6000 \mathrm{psi} .
\end{gathered}
$$

Fracture position is in the center of the reservoir.

Step 1. Plot pressure change $(\Delta p)$ and pressure derivative $(t \times$ $\left.\Delta p^{\prime}\right)$ values versus test time on a log-log graph as shown in Figure 11 .

Step 2. Obtain the best match of the data with one of the type curves as shown in Figure 12.

Step 3. Read from an match point: $t_{M}, t_{D M}, \Delta p_{M}, p_{D M}, w_{z D}$, $w_{x D}, L_{D}$ :

$$
\begin{array}{ccr}
t_{M}=10 \quad t_{D M}=0.11 \quad & \Delta p_{M}=100 \\
p_{D M}=0.05 \quad w_{z D}=0.1 \quad w_{x D}=4 \quad L_{D}=1 .
\end{array}
$$

Step 4. Calculate $k_{h}$ from (31):

$$
k_{h}=\frac{141.2 \times 500 \times 1.4 \times 4 \times 0.05}{100 \times 100}=2 \mathrm{md} .
$$




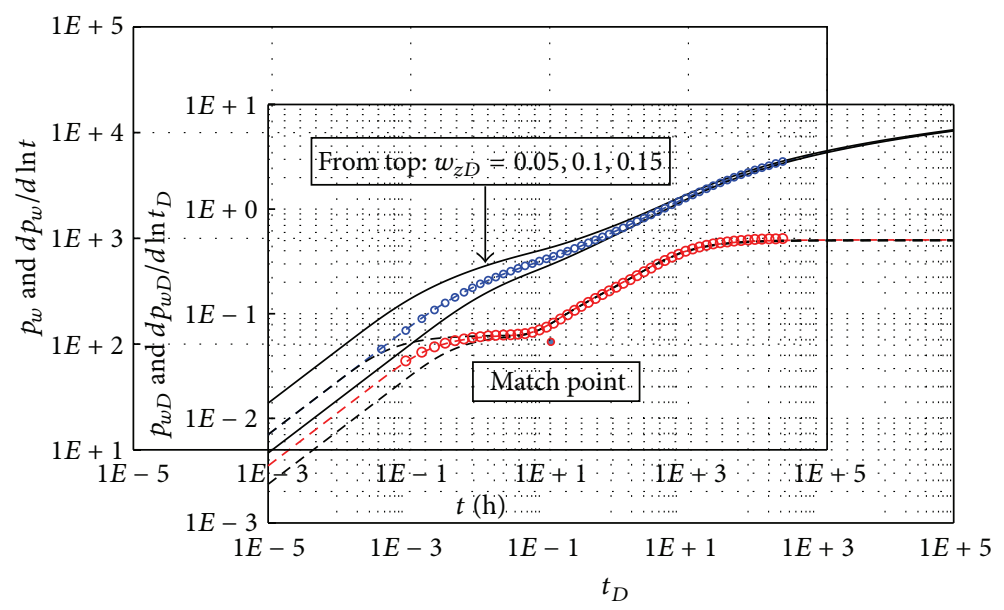

Solid line: $p_{w D}$

Dash line: $d p_{w D} / d \ln t_{D}$

FIgURE 12: Type-curve matching plot for example $\left(w_{x D}=4, L_{D}=1\right)$.

TABLE 2: Results of example.

\begin{tabular}{lcc}
\hline Parameter & Input value & $\begin{array}{c}\text { Calculated value by type } \\
\text { curve matching } \\
\text { technique }\end{array}$ \\
\hline $\begin{array}{l}\text { Horizontal } \\
\text { permeability } k_{h}, \text { md } \\
\text { Vertical permeability } \\
k_{z}, \text { md }\end{array}$ & 2 & 2 \\
$\begin{array}{l}\text { Fracture half length } \\
w_{x}, \mathrm{ft}\end{array}$ & 400 & 2 \\
$\begin{array}{l}\text { Fracture half height } \\
w_{z}, \mathrm{ft}\end{array}$ & 10 & 400 \\
\hline
\end{tabular}

Step 5. Calculate $L$ from (32):

$$
L=\sqrt{\frac{0.0002637 \times 10 \times 2}{0.3 \times 4 \times 4 \times 10^{-6} \times 0.11}}=100 \mathrm{ft} .
$$

Step 6. Calculate $k_{z}$ from (33):

$$
k_{z}=\frac{2}{((100 \times 1) / 100)^{2}}=2 \mathrm{md} .
$$

Step 7. Calculate the fracture half height from (34):

$$
w_{z}=0.1 \times 100=10 \mathrm{ft} .
$$

Step 8. Calculate the fracture half length from (35):

$$
w_{x}=4 \times 100=400 \mathrm{ft} \text {. }
$$

Table 2 compares the input data and the resulting values of the example.

\section{Conclusions}

A detailed step by step procedure for solving the analytical solution of a partially penetrating hydraulic fracture in a box-shaped reservoir by using Fourier cosine transform and Laplace transform is presented. The solution can be used to investigate the pressure transient behavior. In this paper, we validated it available with the published analytical solution for a relative simple system. Sensitivity analyses about the effects of the main parameters including fracture height, fracture length, and reservoir width on type curves are also presented in detail. Moreover the effect of the vertical position of the fracture on the pressure and pressure derivative is fully investigated. And an example is used to illustrate that the type curves can be used to analyze transient well test analysis for partially penetrating fracture in closed reservoirs. The merit of the solution is that it can also reduce the amount of computation and compute efficiently and quickly. The solution can be further developed as its great applicability.

\section{Conflict of Interests}

The authors declare that there is no conflict of interests regarding the publication of this paper.

\section{References}

[1] S. Al Rbeawi and D. Tiab, "Effect of penetrating ratio on pressure behavior of horizontal wells with multiple-inclined hydraulic fractures," in Proceedings of the SPE Western Regional Meeting Aeld in Bakersfield, pp. 1-20, San Diego, Calif, USA, March 2012, SPE paper No. 153788.

[2] S. Al Rbeawi and D. Tiab, "Partially penetrating hydraulic fractures: pressure responses and flow dynamics," in Proceedings of the SPE Production and Operations Symposium, SPE paper no. 164500, pp. 333-360, Oklahoma City, Okla, USA, March 2013.

[3] O. Alpheus and D. Tiab, "Pressure transient analysis in partially penetrating infinite conductivity hydraulic fracture in naturally fractured reservoirs," in Proceedings of the SPE Annual Technical Conference and Exhibition, SPE Paper no. 116733, pp. 1-19, Denver, Colo, USA, September 2008. 
[4] E. Gomes and A. K. Ambastha, "Analytical expressions for pseudoskin for partially penetrating wells under various reservoir conditions," in Proceedings of the 68th Annual Technical Conference and Exhibition of the Society of Petroleum Engineers, pp. 691-706, Houston, Tex, USA, October 1993, SPE Paper No.26484.

[5] T. D. Streltsova-Adams, "Pressure drawdown in a well with limited flow entry," Journal of Petroleum Technology, vol. 31, no. 11, pp. 1469-1476, 1979, SPE-7486-PA.

[6] I. M. Buhidma and R. Raghavan, "Transient pressure behavior of partially penetrating wells subject to bottomwater drive," Journal of Petroleum Technology, vol. 32, no. 7, pp. 1251-1261, 1980.

[7] N. Yeh and A. C. Reynolds, "Analysis of pressure data from a restricted-entry well in a multilayer reservoir," SPE Formation Evaluation, vol. 4, no. 1, pp. 81-15584, 1989.

[8] E. Ozkan and R. Raghavan, "A computationally efficient, transient-pressure solution for inclined wells," in SPE Reservoir Evaluation \& Engineering, pp. 414-425, October 2000, SPE Paper No. 49085.

[9] T. D. Bui, D. D. Mamora, and W. J. Lee, “Transient pressure analysis for partially penetrating wells in naturally fractured reservoirs," in Proceedings of the SPE Rocky Mountain Regional/Low Permeability Reservoirs Symposium and Exbibition, SPE Paper No. 60289, pp. 1-8, Denver, Colo, USA, March 2000.

[10] G. Fuentes-Cruz and R. Camacho-Velazquez, "Pressure transient and decline curve behaviors for partially penetrating wells completed in naturally fractured-vuggy reservoirs," in Proceedings of the SPE International Petroleum Conference in Mexico, SPE Paper 92116, pp. 1-14, Puebla, Mexico, November 2004.

[11] A. C. Gringarten and H. J. Ramey, "The use of source and Green's function in solving unsteady-flow problem in reservoir," SPE Paper 3818, Society of Petroleum Engineers, 1973.

[12] A. C. Gringarten and H. J. Ramey Jr., "Unsteady-state pressure distributions created by a well with a single horizontal fracture, partial penetration, or restricted entry," SPE Paper No. 3819, SPE, 1974.

[13] R. Raghavan, A. Uraiet, and G. W. Thomas, "Vertical fracture height: effect on transient flow behavior," in Proceedings of the SPE-AIME Annual Fall Technical Conference and Exhibition, pp. 265-277, August 1978, SPE Paper No. 6016.

[14] F. Rodriguez, R. N. Horne, and H. Cinco-Ley, "Partially penetrating fractures: pressure transient analysis of an infinite conductivity fracture," in Proceedings of the California Regional Meeting, SPE Paper no. 12743, pp. 163-177, Long Beach, Calif, USA, April 1984.

[15] F. Rodriguez, R. N. Horne, and H. Cinco-Ley, "Partially penetrating vertical fractures: pressure transient behavior of a finite-conductivity fracture," in Proceedings of the 59th Annual Technical Conference and Exhibition, SPE Paper no. 13057, pp. 1-4, Houston, Tex, USA, September 1984.

[16] P. P. Valkó and S. Amini, "The method of distributed volumetric sources for calculating the transient and pseudosteady-state productivity of complex well-fracture configurations," in Proceedings of the SPE Hydraulic Fracturing Technology Conference, SPE paper 106279, pp. 1-14, January 2007.

[17] J. Lin and D. Zhu, "Predicting well performance in complex fracture systems by slab source method," in Proceedings of the SPE Hydraulic Fracturing Technology Conference, SPE Paper 151960, pp. 1-15, The Woodlands, Tex, USA, February 2012.
[18] H. Stehfest, "Algorithm 368: numerical inversion of laplace transforms," Communications of the ACM, vol. 13, no. 1, pp. 4749, 1970.

[19] F. Kuchuk and W. E. Brighan, "Transient flow in elliptical systems," Tech. Rep. SPE-7488-PA, Society of Petroleum Engineers, December 1979. 


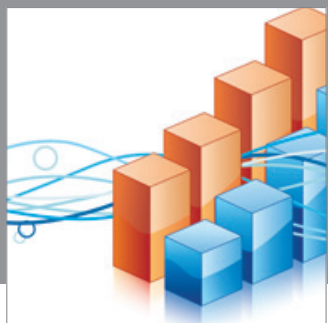

Advances in

Operations Research

mansans

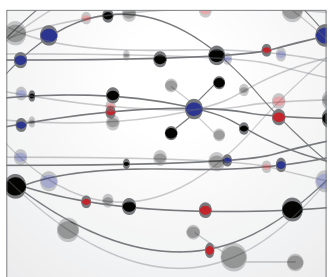

The Scientific World Journal
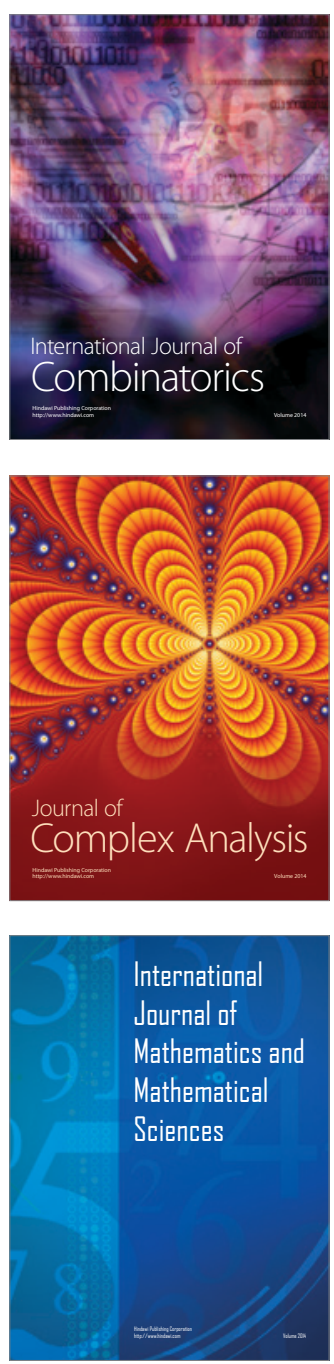
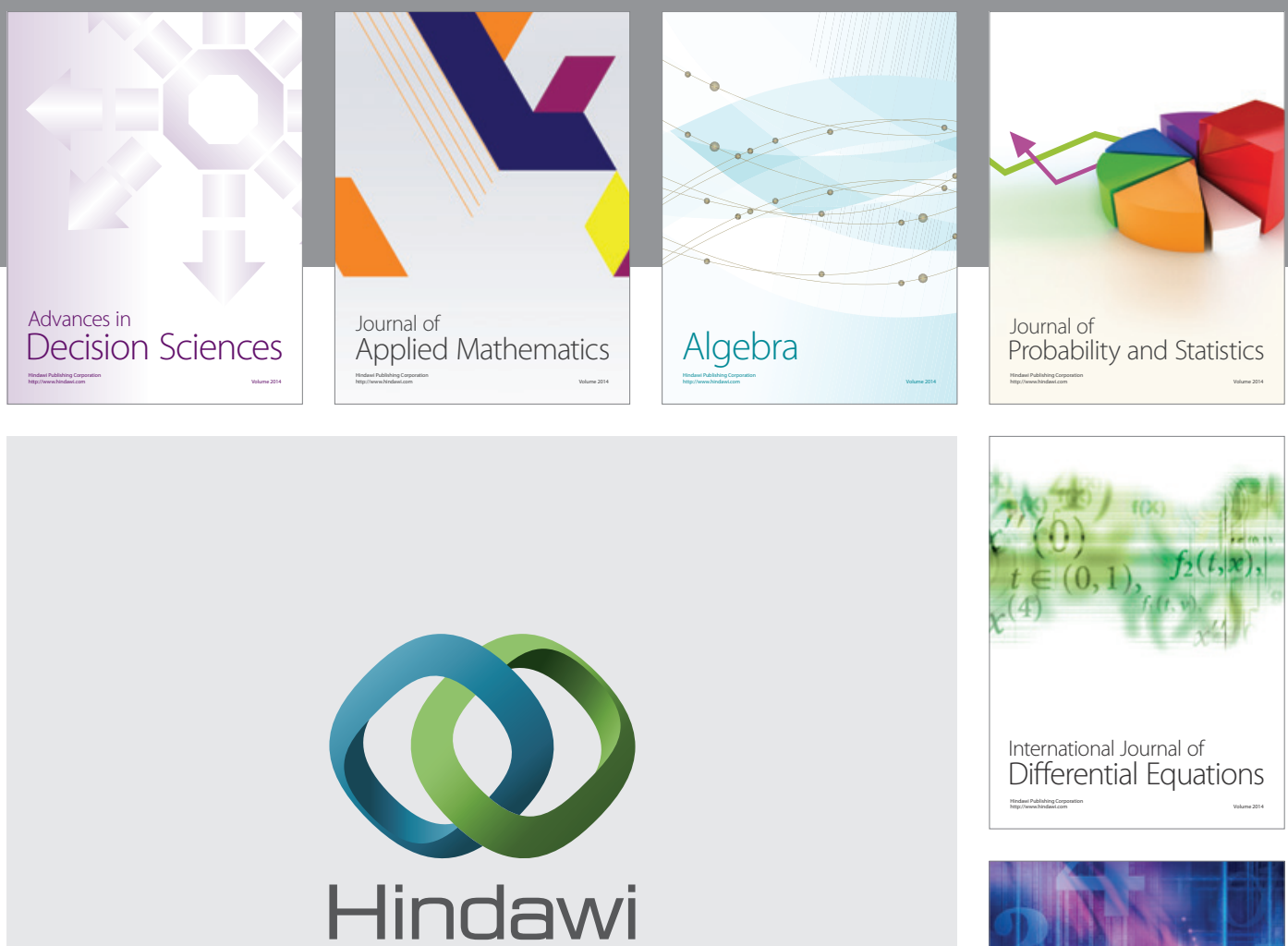

Submit your manuscripts at http://www.hindawi.com
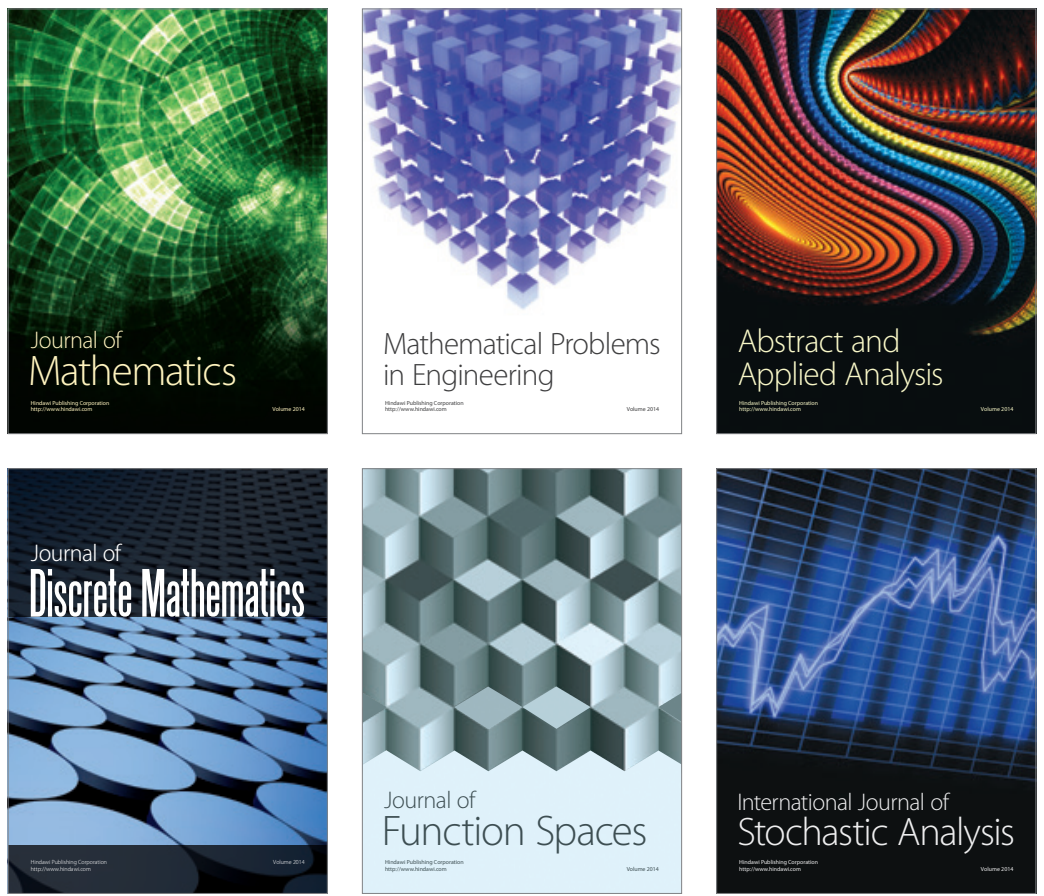

Journal of

Function Spaces

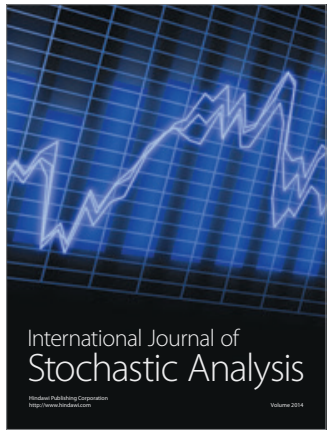

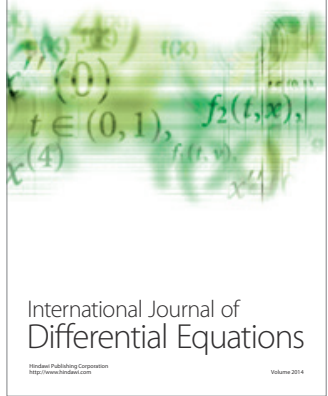
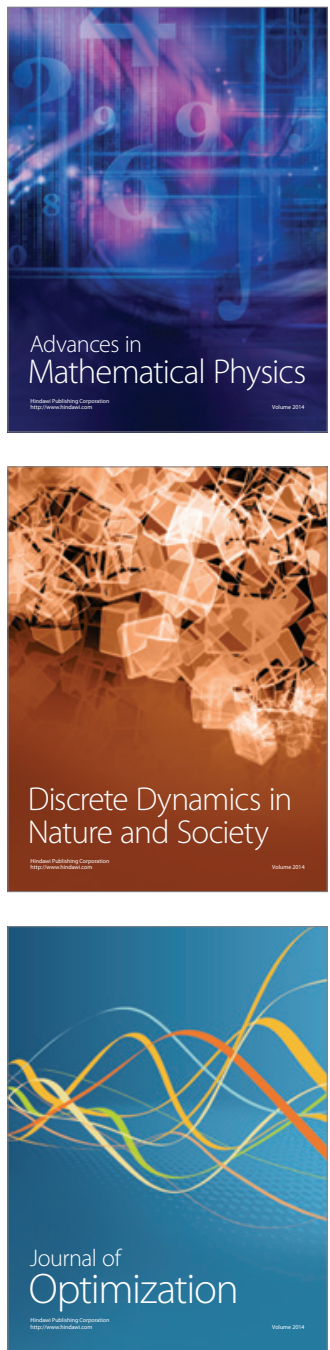